\title{
A Study on Distribution Measurement and Mechanism of Deformation due to Water Loss of Overburden Layer in Vertical Shaft
}

\author{
Chunde Piao, Jun Yuan, Dangliang Wang, and Pengtao Li \\ School of Resources and Geosciences, China University of Mining and Technology, Xuzhou, Jiangsu 221116, China \\ Correspondence should be addressed to Chunde Piao; piaocd@126.com
}

Received 17 October 2014; Accepted 30 November 2014

Academic Editor: Fei Dai

Copyright (C) 2015 Chunde Piao et al. This is an open access article distributed under the Creative Commons Attribution License, which permits unrestricted use, distribution, and reproduction in any medium, provided the original work is properly cited.

\begin{abstract}
Based on FBG fiber Bragg grating technology and BOTDA distributed optical fiber sensing technology, this study uses fine sand to simulate overburden layer in vertical shaft model equipment. It studies the placing technique and test method for optical fiber sensors in the overburden layer, combined with MODFLOW software to simulate the change of the water head value when the overburden layer is losing water, and obtains the deformation features of overburden layer. The results show, at the beginning of water loss, the vertical deformation increases due to larger hydraulic pressure drop, while the deformation decreases gradually and tends to be stable with the hydraulic pressure drop reducing. The circumferential deformation is closely related to such factors as the distance between each drainage outlet, the variations of water head value, and the method of drainage. The monitoring result based on optical fiber sensing technology is consistent with the characteristics of water loss in overburden layer simulated by MODFLOW software, which shows that the optical fiber sensing technology applied to monitor shaft overburden layer is feasible.
\end{abstract}

\section{Introduction}

A series of problems have cropped up in coal mining; the shaft lining rupture and local buckling deformation are always major problems [1]. Since the mine disaster is caused by rupture of shaft lining, through a large number of theoretical studies and testing data, it is proved that the vertical additional force which results from consolidation settlement due to drainage in thick overburden is the major factor which could lead to rupture of shaft lining [2]. At present, to monitor the shaft deformation, most researches analyze stability of the shaft lining structure by geometric metrology or the sensors installed in the outer part of shaft lining, but monitoring methods of overburden settlement are studied less before [3]. If overburden could be effectively monitored and the hydrophobic settlement deformation characteristics could be immediately recognized during operation of shaft lining, the fatal accidents will be avoided through effective measures.

As one of the most promising technologies in fiber optic sensor, distributed optical fiber sensing technology has many advantages, such as distributed monitor, long distance, antielectromagnetic interference, corrosion resistance, great durability, small size, and light weight. This technology has been widely used in engineering field including slope [47], pile foundation [8], and tunnel [9]. Facing the current situation of serious rupture of shaft lining, this paper, based on FBG fiber grating technology and BOTDA optical fiber sensing technology, uses the test device of shaft model, studies the placing technique for optical fiber sensors in the overburden layer, establishes the monitoring method based on optical fiber sensing technology, and analyzes hydrophobic settlement deformation characteristics, thus providing a firm theoretical and technical support for the exploitation of coal resources.

\section{Optical Fiber Sensor Monitoring Technique}

2.1. Fiber Bragg Grating Technology. In 1978, Hill et al. at Communications Research Centre in Ottawa, Canada, first found photosensitivity in a Germanium-doped silica fiber and made the first optical fiber grating sensor by using standing wave method [10]. With increasing researches all 
over the world, fiber Bragg grating (FBG) sensor has become the most widely used optical fiber sensor in structural health monitoring. The basic principle of fiber Bragg grating sensor is that when the broadband incident light enters the fiber, the light which meets wave length conditions of Bragg grating will be reflected to become reflection light, and the rest of the light will become transmitted light. External temperature and strain changes will cause wavelength shift of reflection light, so by detecting the change of center wavelength, the change of measured signal can be obtained. The relationship between the strain and the center wavelength of fiber grating plus temperature is shown as follows $[11,12]$ :

$$
\frac{\Delta \lambda_{B}}{\lambda_{B}}=c_{\varepsilon} \Delta \varepsilon+c_{T} \Delta T .
$$

In the formula above, $\lambda_{B}$ is the initial central wavelength of reflection light, and $\Delta \lambda_{B}$ is the drift amount of central wavelength. $\Delta \varepsilon$ and $\Delta T$ are the variable quantity of strain and temperature, respectively. $c_{\varepsilon}$ and $c_{T}$ refer to strain coefficient and temperature coefficient of fiber Bragg grating, respectively. At present, temperature accuracy of fiber Bragg grating is $0.1^{\circ} \mathrm{C}$ and strain accuracy is $1 \mu \varepsilon$.

2.2. Brillouin Optical Time-Domain Analysis. Brillouin optical time-domain analysis (BOTDA) was first proposed by Horiguchi et al. in 1989. It was then applied to fiber nondestructive measurement in fiber communication field, and its spatial resolution was $100 \mathrm{~m}$ and strain accuracy was $100 \mu \varepsilon$ [13].

Kishida et al. introduced the prepumped pulse method based on the theory model of leakage light pumped pulse. The Neubrex Company developed type NBX-6000 PulsePrePump-Brillouin Optical Time-Domain Analyzer (PPPBOTDA) [14]. In terms of the measuring principle of PPPBOTDA, it works by changing the structure of pumping laser pulse, during which both ends of fiber are, respectively, injected with step index pump pulse light and continuous light, and prepump pulse stimulates acoustic wave before pump pulse arrives at detection zone; thus, prepump pulse, pump pulse, probe laser, and stimulated acoustic wave interact with each other in the fiber, creating stimulated Brillouin scattering. Through the continuous frequency adjustment of the exploring laser light source, the continuous light power output is detected from the other end of fiber, which determines the frequency difference when fiber's Brillouin gains maximum in every small area, and this frequency difference is equal to fiber's Brillouin frequency shift in each part of area. Thus, according to the linear relation of Brillouin frequency shift and strain temperature, the change of strain and temperature can be determined on the various points along the fiber and it is shown in the following formula [15]:

$$
v_{B}(\varepsilon, T)=v_{B}(0)+\frac{d v_{B}(\varepsilon)}{d \varepsilon} \cdot \varepsilon+\frac{d v_{B}(T)}{d T} \cdot\left(T-T_{0}\right) .
$$

In the formula above, $v_{B}(\varepsilon, T)$ is the drift amount of fiber Brillouin frequency with the change of strain and temperature, while $v_{B}(0)$ is the drift amount of fiber Brillouin frequency without the change of strain and temperature. $\varepsilon$ is

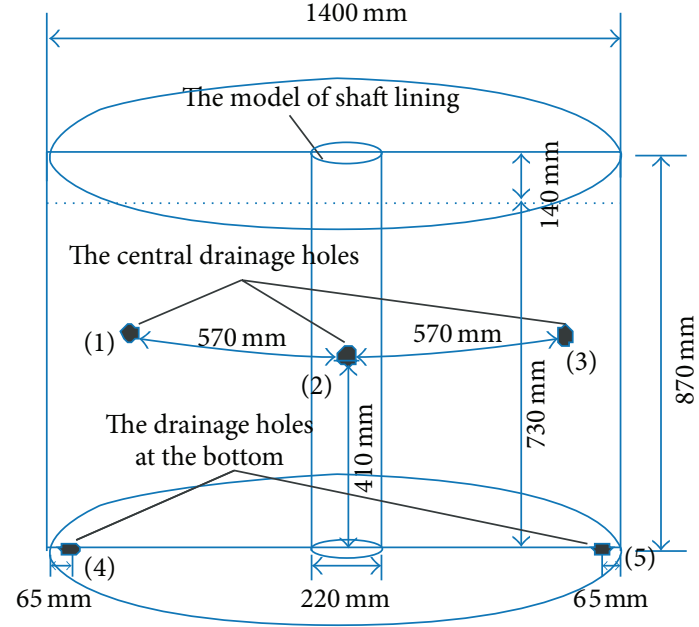

FIgURE 1: The size of shaft lining model equipment.

the axial dependent variable of sensing optical fiber. $\left(T-T_{0}\right)$ is the variable quantity of external temperature. $d v_{B}(\varepsilon) / d \varepsilon$ and $d v_{B}(T) / d T$ refer to influence coefficient of strain and temperature, respectively.

At present, the minimum spatial resolution of $10 \mathrm{~cm}$ can be reached and strain accuracy is $25 \mu \varepsilon$ in measurement range of $1 \mathrm{~km}$ when this measurement technique is applied.

\section{Model Test on Deformation in Overburden Layer}

3.1. Test Scheme. Through simulating overburden layer with fine sand, this experiment uses the self-made vertical shaft model equipment to study the settlement and deformation, which results from the drainage in overburden layer. The diameter of the model equipment is $1400 \mathrm{~mm}$, the height is $870 \mathrm{~mm}$, and the diameter of the shaft lining is $220 \mathrm{~mm}$. There are two drainage outlets at the bottom of the model equipment and three central drainage outlets are $410 \mathrm{~mm}$ above from the bottom, with the diameter of all drainage outlets being $20 \mathrm{~mm}$. The height of fine sand is $730 \mathrm{~mm}$. During the test medium, the nonuniform coefficient $(\mathrm{Cu})$ of fine sand is 2.56 , and the curvature coefficient $(\mathrm{Cc})$ is 1.03 . The permeability coefficient is $9 \mathrm{~m} / \mathrm{d}$; the water storage capacity is 0.1 ; the effective porosity is 0.1 . The specific size of the model equipment is shown in Figure 1.

To measure the vertical settlement and circumferential deformation caused by the overburden losing water, we lay FBG optical fiber grating sensors and tight buffered optical fibers on the vertical and circumferential directions. Based on the layout scheme, $200 \mathrm{~mm}$ above from the bottom of the model equipment, we put every $100 \mathrm{~mm}$ distance, 5 circumferential tight buffered fibers, whose circumferential radius is $400 \mathrm{~mm}$ away from shaft lining. The iron plate with width of about $20 \mathrm{~mm}$ and length of about $750 \mathrm{~mm}$ is installed about $200 \mathrm{~mm}$ away from the shaft lining between the shaft lining and the central drainage hole 2. Five sensors FBG are pasted onto the iron plate whose length is $10 \mathrm{~mm}$. The layout 


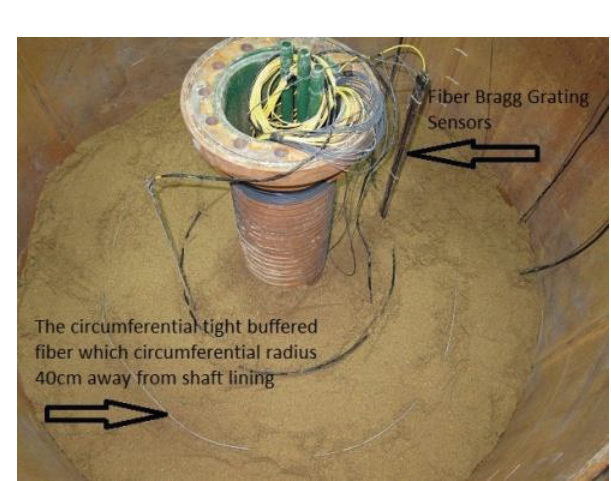

(a) The layout method of optical fiber sensors

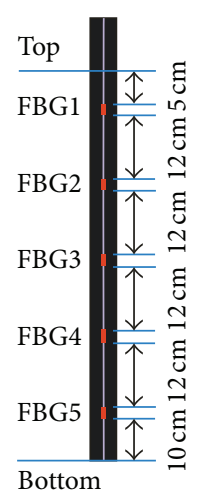

(b) The size of FBG optical fiber grating sensors

Figure 2: The layout method of optical fiber sensors and the size of FBG optical fiber grating sensors.

method of optical fiber sensors and the size of FBG optical fiber grating sensors are shown in Figure 2. The sensors FBG2 and FBG3 fail during the test.

The bearing plate with thickness of $10 \mathrm{~mm}$ and diameter of $1360 \mathrm{~mm}$ is set on the top of fine sand layer in the experiment, whose weight is about $745 \mathrm{~N}$. The jack and the weight are installed on the bearing plate to simulate soil pressure. The test is carried out in two steps. The first step is putting the weights of $1000 \mathrm{~N}, 3000 \mathrm{~N}$, and $5000 \mathrm{~N}$ on the bearing plate to study the vertical and circumferential deformation of fine sand layer in the function of the upper pressure before water injection test. The second step is injecting water into the top of fine sand layer and then opening both central drainage outlets and bottom drainage outlets simultaneously, in order to study consolidation settlement and circumferential deformation of fine sand layer caused by the drainage.

\subsection{Analysis on Water Loss of Fine Sand Layer by MODFLOW} Software. Based on the model of shaft lining, this study uses the finite difference software Visual MODFLOW to construct the two-dimensional seepage model and obtain the change of head value when the fine sand layer loses water. The central drainage outlets and the drainage outlets at the bottom are opened at the same time. Figure 3 is the variation distribution map of water head value when the fine sand layer begins to lose water, and Figure 4 is the variation distribution map of water head value when the water level reaches the central drainage outlets.

From Figures 3(a) and 3(c), at drainage time, the water head value on both top and bottom of overburden layer has relatively minor change. However, Figure 3(b) shows that, under the influence of central drainage outlets, the water head value of plane $0.41 \mathrm{~m}$ away from the bottom changes significantly, yet its influence scope is only near the drainage outlets. As shown in Figure 4(a), when the water level reaches $0.41 \mathrm{~m}$, the water head value near the drainage outlets decreases considerably, and the range of influence is between the central drainage outlets and the headline whose value is 0.46 , but the value at other positions remains unaffected. Figure 4(b) shows that, near the drainage outlets at the bottom, the water head value of plane $0 \mathrm{~m}$ will drop, but its influence range is relatively small.

\section{Result Analysis on Deformation Monitoring of Overburden Layer}

4.1. Settlement and Compression Deformation of Overburden Layer Caused by Loading. As is shown in Figure 5, the deformation of fine sand layer, monitored by the sensors FBG1, FBG4, and FBG5, changes with time, when the bearing plate is bearing the weights of $1000 \mathrm{~N}, 3000 \mathrm{~N}$, and $5000 \mathrm{~N}$.

From Figure 5, it can be found that the deformation of fine sand layer gradually increases with the load increasing under changeable load, while the deformation gradually decreases with the depth increasing. For the sensors FBG4 and FBG5 at the bottom of fine sand layer, the deformation curve takes on an obvious form of stepladder because the fine sand layer completes settlement and tends to be stable within a short period of time. For the sensor FBG1 installed on the top of fine sand layer, the deformation is small and temporary with lower loads. When loads increasing, the soil pore is gradually filled with solid particles and the linear deformation intensifies.

Based upon BOTDA distributed fiber sensing technology, we detect the annulus sensing fiber, which is $40 \mathrm{~cm}$ far away from the shaft lining, and get the value of the circumferential deformation of fine sand layer under changeable loads, as is shown in Figure 6.

Figure 6 shows that the circumferential deformation of fine sand layer increases with the load rising, and its value gradually drops from the top to bottom; only soil is compressed under load, and the change of hoop strain at the same level stays the same.

4.2. Settlement and Compression Deformation Caused by Water Loss of the Aquifer. In the experiment, we apply $5000 \mathrm{kN}$ load to the laminate on the top of overburden layer and inject water into the model equipment of shaft by the central drainage outlets. Then till the fine sand layer is submerged, we subsequently open both central and bottom drainage outlets and analyze the settlement character of the mineshaft during the process. During the experiment, the water level reaches the central drainage outlets after injecting water to the shaft for about 80 minutes. The fine sand layer continues to lose water through the drainage outlets at the bottom with time going on. The settlement character of the fine sand layer when losing water can be seen in Figure 7.

As shown in Figure 7, during the fine sand layer losing water, the effective stress increases and the pore water pressure decreases [16]. The fine sand is in transition from loose state to dense state and gradually stabilizes from top to bottom. The deformation of the sensors depends on buried depth and water losing conditions. For the sensor FBG1 at the top of sand layer, the deformation increases when the initial hydraulic pressure drop is great. With the decrease of hydraulic pressure drop, the deformation gradually decreases and tends to be stable. For the sensor FBG4, the fine sand 


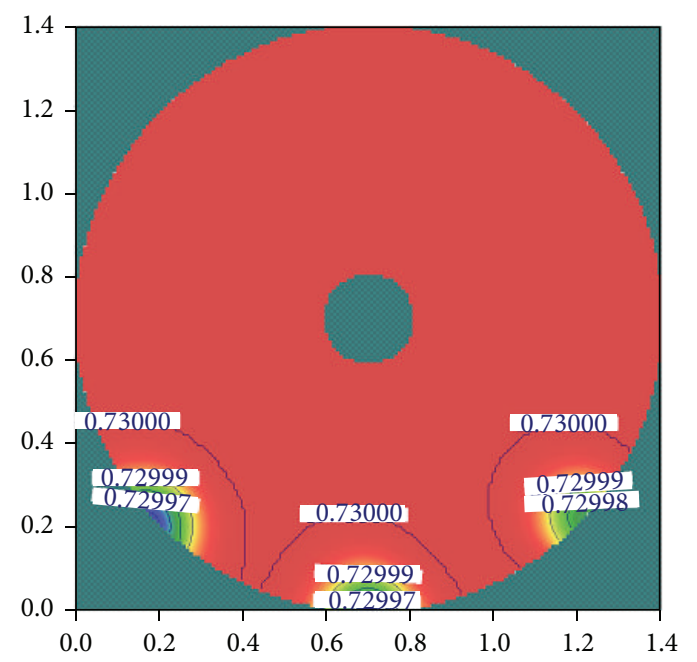

(a) The plane on top of overburden layer

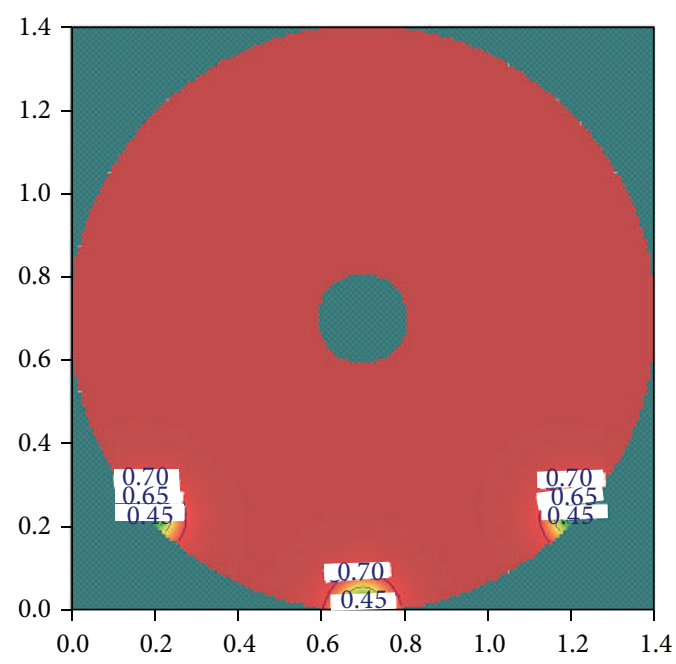

(b) The plane $0.41 \mathrm{~m}$ away from the bottom

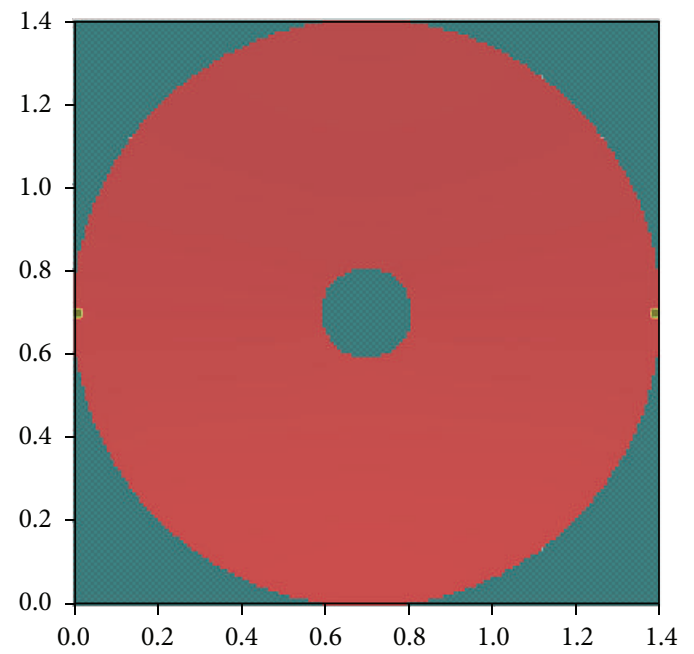

(c) The plane on bottom of overburden layer

FIGURE 3: The distribution map showing the variation of water head value of overburden layer at drainage time.

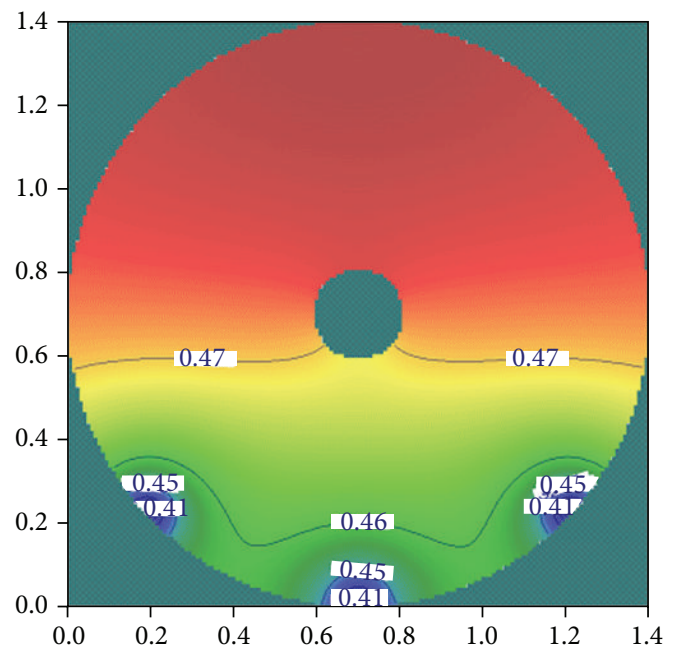

(a) The plane $0.41 \mathrm{~m}$ away from the bottom

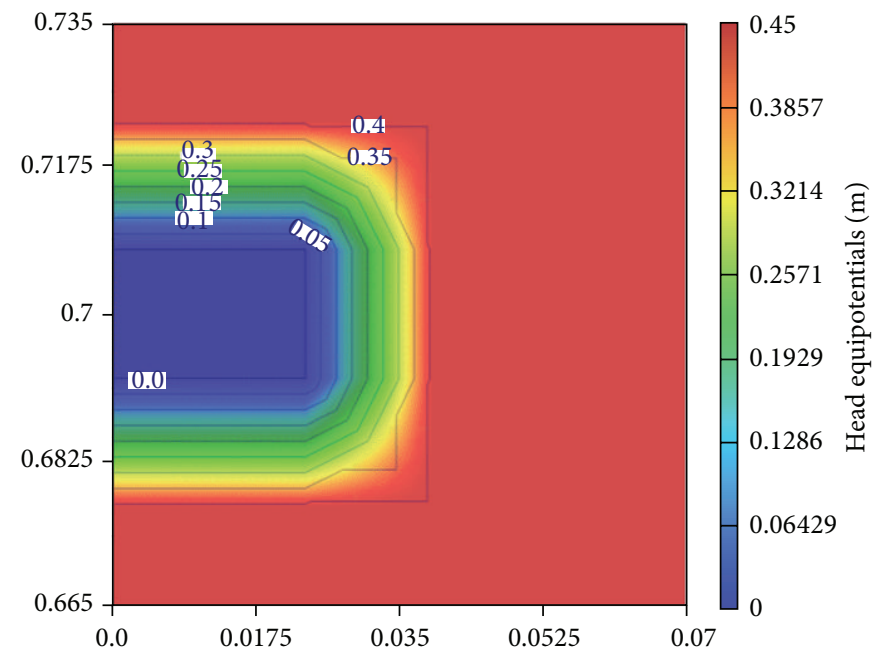

(b) The plane on bottom of overburden layer

Figure 4: The distribution map of the variation of water head value of overburden layer when the water level reached $0.41 \mathrm{~m}$. 


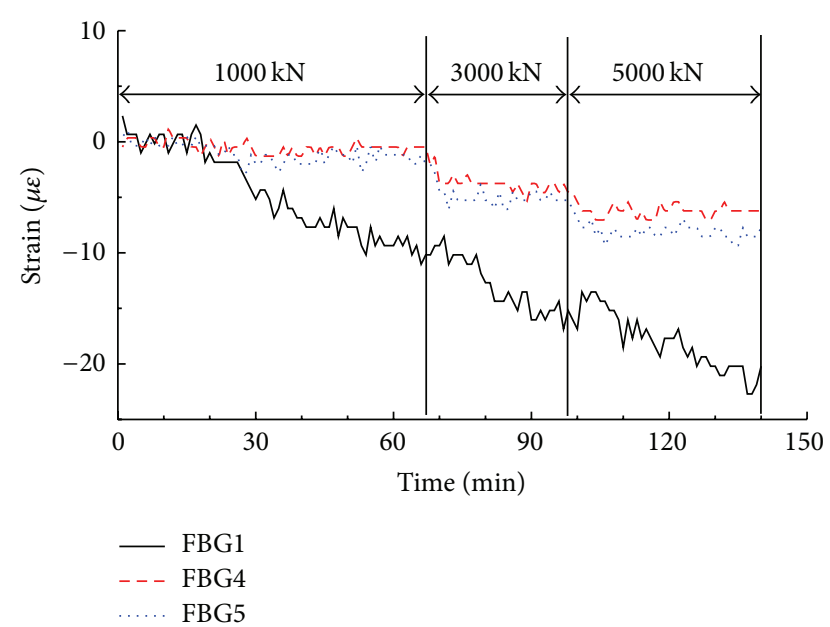

FIGURE 5: Dependent variable of fine sand layer along with variation of time under load.

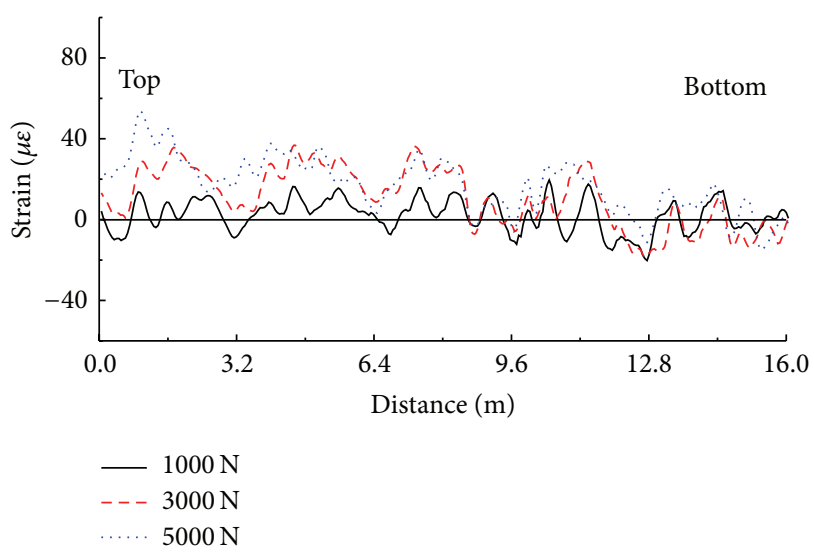

Figure 6: Circumferential deformation of fine sand layer $40 \mathrm{~cm}$ away from the shaft lining under load.

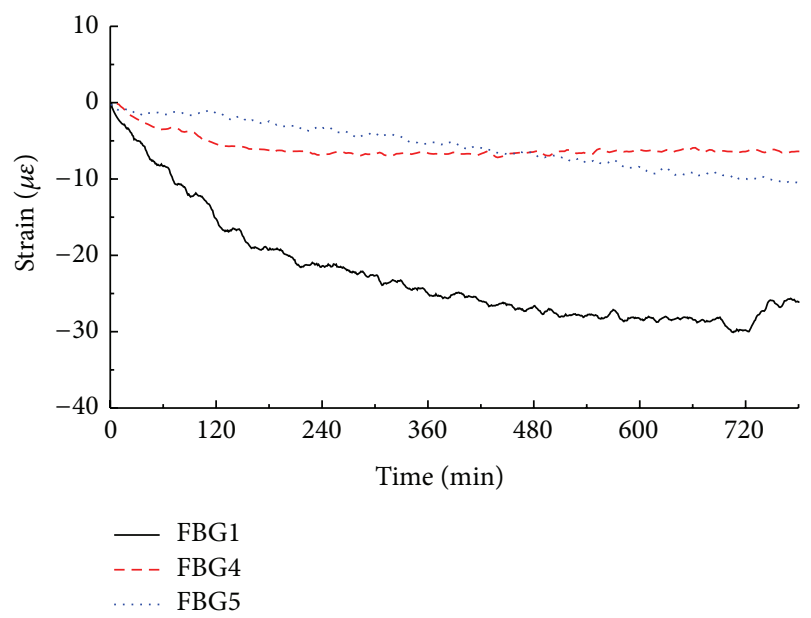

FIGURE 7: Dependent variable of fine sand layer along with variation of time under water loss.

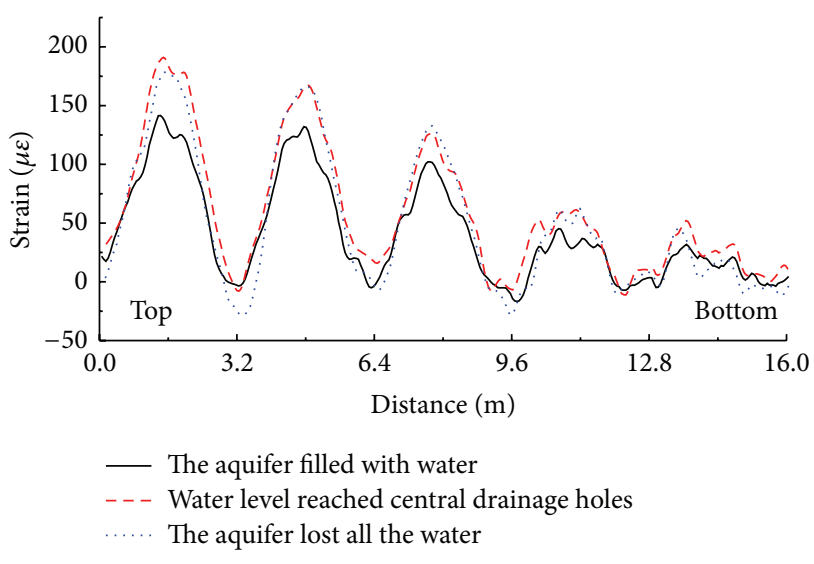

Figure 8: Circumferential deformation of fine sand layer $40 \mathrm{~cm}$ away from the shaft lining under water loss.

deformation increases gradually with its water loss. As the sensor has been located below the drainage outlets of the central shaft, the deformation caused by water loss is smaller. FBG5 has been laid at the bottom of the sand layer, and the deformation of the sand layer is relatively small at the beginning. Yet when aquifer loses water only via the bottom drainage outlets, the porosity rises and the deformation of aquifer increases linearly under the monitoring of sensor FBG5.

According to the change of water head value illustrated in Figure 4, along with the curve of circumferential strain shown in Figure 8, it can be found that affected by the loss of water in central drainage outlets, with the reducing distance from the drainage outlets, the porosity of the sand layer increases while the density decreases, so the circumferential deformation value of the fine sand layer increases, and the deformation value becomes stable while the change of water head is relatively smaller.

Figure 8 is the curve of circumferential strain of fine sand layer during losing water, which has been detected by BOTDA.

According to the curves of circumferential strain in Figures 6 and 8, without considering overburden pressure, the circumferential strain distribution can be obtained when the sand layer loses water. At the same plane of sand layer, the circumferential deformation is related to the distance between each drainage outlet, the variations of the water head value, and the method of drainage. When the drainage outlets are set in the middle, because of water loss of the aquifer, the water head value changes obviously and the deformation increases, as the distance between water level and the drainage outlets reduces. When the drainage outlets are set at the bottom, affected by water quantity, only the water head value near the drainage outlets changes and the circumferential deformation tends to undergo a uniform change. In vertical direction, when water level of saturated fine sand layer decreases to the central drainage outlets, the deformation near the drainage outlets gradually decreases from top to bottom while the dependent variable far away from the drainage outlets keeps invariant without 
any variation in the water head value. When the pore water is excreted out of the aquifer only through the drainage outlets at the bottom, the settlement of soil is homogeneous and there is nearly no circumferential deformation.

\section{Conclusions}

Based on the above analysis, the main conclusions can be drawn as follows.

(1) According to the monitoring results of settlement by FBG fiber Bragg grating technology, the vertical deformation of fine sand layer depends on water losing conditions and buried depth of the sensors. Under the same load, the force on the soil at the bottom of shaft is smaller, and the soil tends to be stable in a short period of time, during which the deformation curve takes on an obvious form of stepladder, yet meanwhile the force on the soil on the top of shaft is larger, and the soil tends to be stable for a long period of time. The hydraulic pressure drop of the soil on the top of shaft is larger and the deformation increases at the initial stage of water loss, while the deformation decreases gradually and tends to be stable with the hydraulic pressure drop reducing.

(2) The monitoring result of overburden layer based on BOTDA distributed optical fiber sensing technology shows that the circumferential deformation is connected with such factors as the distance between each drainage outlet, the change in the water head value, and the method of drainage. When the drainage outlets are set in the middle, with water level of saturated fine sand layer decreasing to the central drainage outlets, the water head value, caused by the aquifer losing water, changes significantly as the distance between water level and the drainage outlets reduces. Near the drainage outlets, the deformation gradually decreases from top to bottom, yet when it is far away from the drainage outlets, the dependent variable remains the same. When the drainage outlets are set at both ends of the bottom, the pore water is running out only through the drainage outlets at the bottom. Then it is only near the drainage outlets that the water head value changes. And the circumferential deformation is almost in uniform change.

(3) Based on FBG fiber Bragg grating technology and BOTDA distributed fiber sensing technology, the study obtains deformation features of overburden layer under the water losing conditions. The research result is consistent with the characteristics of overburden layer losing water simulated by MODFLOW software. It shows that, in monitoring shaft overburden layer, the placing technique and test method for optical fiber sensors are plausible.

\section{Conflict of Interests}

The authors declare that there is no conflict of interests regarding the publication of this paper.

\section{Acknowledgments}

The work is funded by National Science Foundation for Youth (no. 51004103), China Postdoctoral Science Foundation (no. 20100481175), and the Project Funded by the Priority Academic Program Development of Jiangsu Higher Education Institutions.

\section{References}

[1] W. Sui, G. Zhang, Z. Jiang et al., "The state-of-the-art of chemical grouting treatment for quicksand hazards in coal mines and the prospect of several key problems," Journal of Engineering Geology, vol. 1, supplement 1, pp. 73-77, 2008.

[2] H. Lv, W. Yang, X. Cheng et al., "The research on mechanism and control techniques of the shaft lining rupture under special strata (the second)," Journal of China University of Mining \& Technology, vol. 26, no. 2, pp. 1-4, 1997.

[3] Z.-Q. Liu, G.-Q. Zhou, G.-S. Zhao, H.-C. Liang, and J.-S. Zhou, "The control method and its application about the soil grouting reinforcement process in vertical shaft," Journal of the China Coal Society, vol. 30, no. 4, pp. 472-475, 2005.

[4] H. Zhu, B. Shi, and J. Zhang, "Distributed fiber optic monitoring and stability analysis of a model slope under surcharge loading," Journal of Mountain Science, vol. 11, no. 4, pp. 979-989, 2014.

[5] H.-H. Zhu, A. N. L. Ho, J.-H. Yin, H. W. Sun, H.-F. Pei, and C.-Y. Hong, "An optical fibre monitoring system for evaluating the performance of a soil nailed slope," Smart Structures and Systems, vol. 9, no. 5, pp. 393-410, 2012.

[6] H.-H. Zhu, B. Shi, J.-F. Yan, J. Zhang, C.-C. Zhang, and B.J. Wang, "Fiber Bragg grating-based performance monitoring of a slope model subjected to seepage," Smart Materials and Structures, vol. 23, no. 9, Article ID 095027, 2014.

[7] Y. Ding, B. Shi, H.-L. Cui, W.-B. Suo, and L. Liu, "A fiber optic sensing net applied in slope monitoring based on Brillouin scattering," Chinese Journal of Geotechnical Engineering, vol. 27, no. 3, pp. 338-342, 2005.

[8] C.-D. Piao, B. Shi, G.-Q. Wei, Y.-Q. Zhu, and D. Zhang, "Application of distributed fiber optic sensing techniques in bored pile detection," Chinese Journal of Geotechnical Engineering, vol. 30, no. 7, pp. 976-981, 2008.

[9] B. Shi, X.-J. Xu, D. Wang et al., "Study on BOTDR-based distributed optical fiber strain measurement for tunnel health diagnosis," Chinese Journal of Rock Mechanics and Engineering, vol. 24, no. 15, pp. 2622-2628, 2005.

[10] K. O. Hill, Y. Fujii, D. C. Johnson et al., "Potosensitivity in optical fiber waveguides: application to reflection filter fabrication," Applied Physics Letters, vol. 32, no. 10, pp. 647-649, 1978.

[11] A. Othonos and K. Kalli, Fiber Bragg Gratings: Fundamentals and Applications in Telecammunications and Sensing, Artech House, London, UK, 1999.

[12] H. Zhu, J. Yin, C. Hong et al., "Fiber optic based monitoring technologies of slope engineering," Geotechnical Investigation \& Surveying, no. 3, pp. 6-9, 2010. 
[13] T. Horiguchi, T. Kurashima, and M. Tateda, "Tensile strain dependence of Brillouin frequency shift in silica optical fibers," IEEE Photonics Technology Letters, vol. 1, no. 5, pp. 107-108, 1989.

[14] K. Kishida, C. S. Li, and S. Lin, "Pulse pre-pump method to achieve $\mathrm{cm}$-order spatial resolution in Brillouin distributed measuring technique," Technical Report of IEICE, OFT, vol. 47, pp. 15-20, 2004.

[15] T. Guo, A. Li, Y. Song, B. Zhang, Y. Liu, and N. Yu, "Experimental study on strain and deformation monitoring of reinforced concrete structures using PPP-BOTDA," Science in China Series E: Technological Sciences, vol. 52, no. 10, pp. 2859-2868, 2009.

[16] G. Chen, T. Li, and Y. He, "Formation mechanism of groundwater for the land subsidence," Research Journal of Chemistry and Environment, vol. 16, no. s2, pp. 56-62, 2012. 

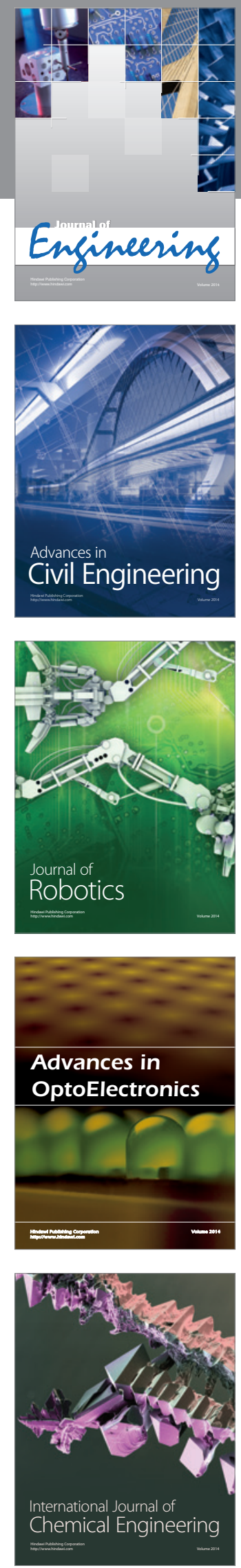

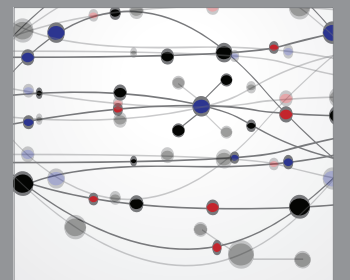

The Scientific World Journal
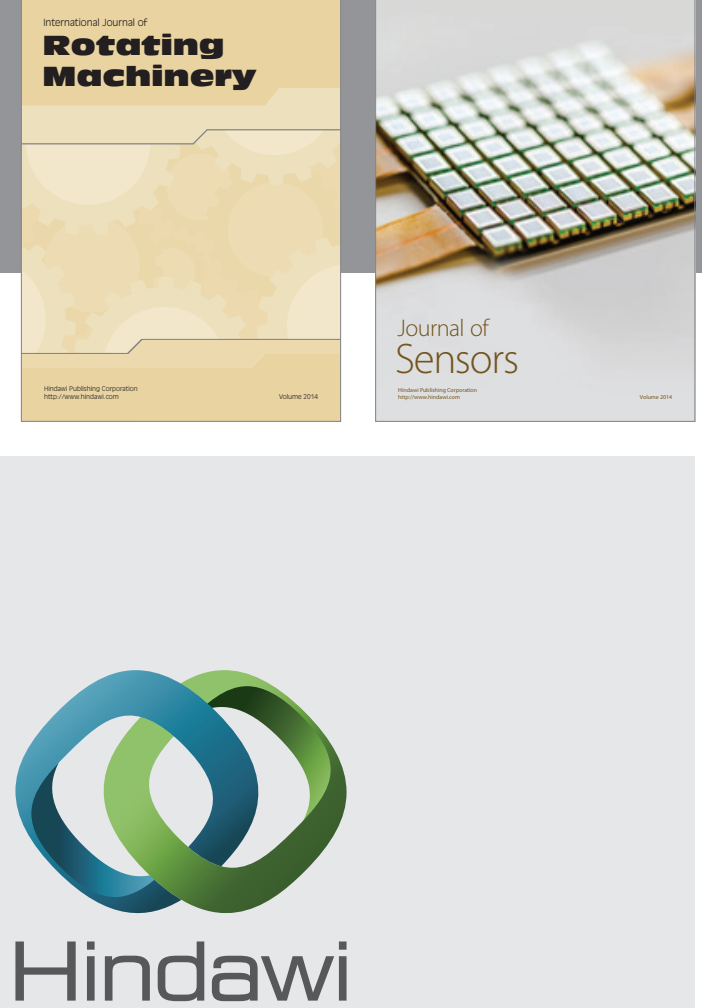

Submit your manuscripts at http://www.hindawi.com
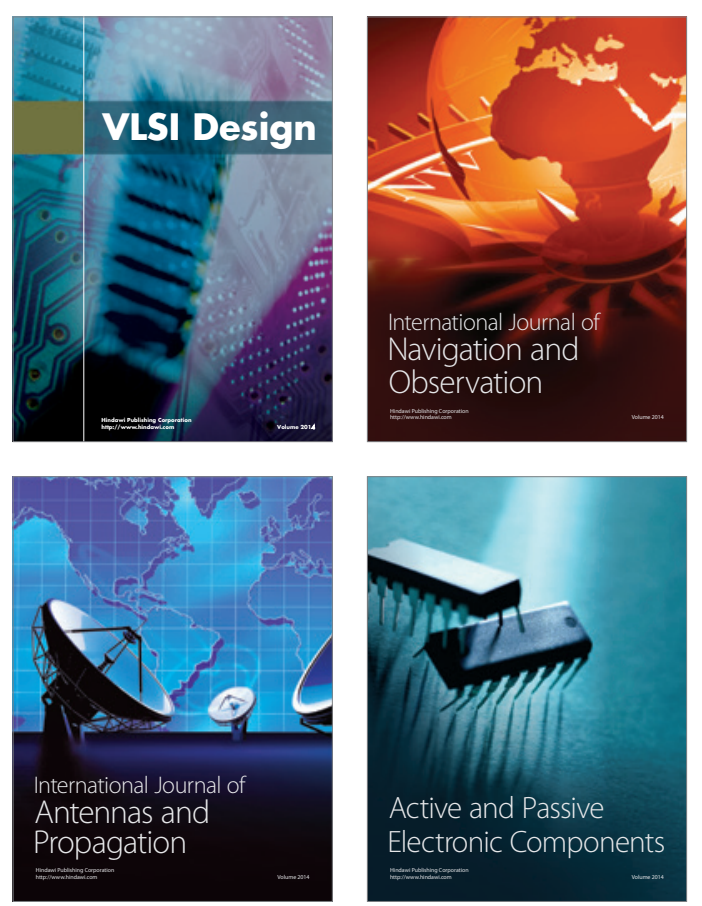
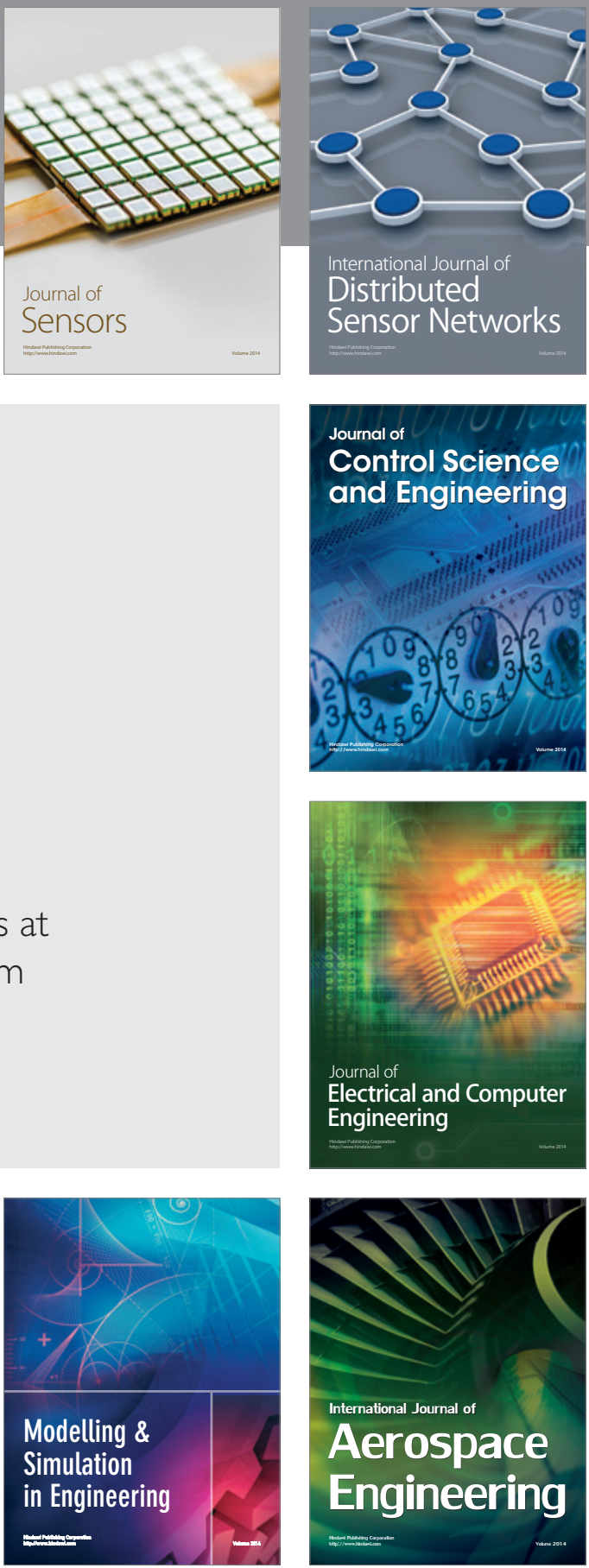

Journal of

Control Science

and Engineering
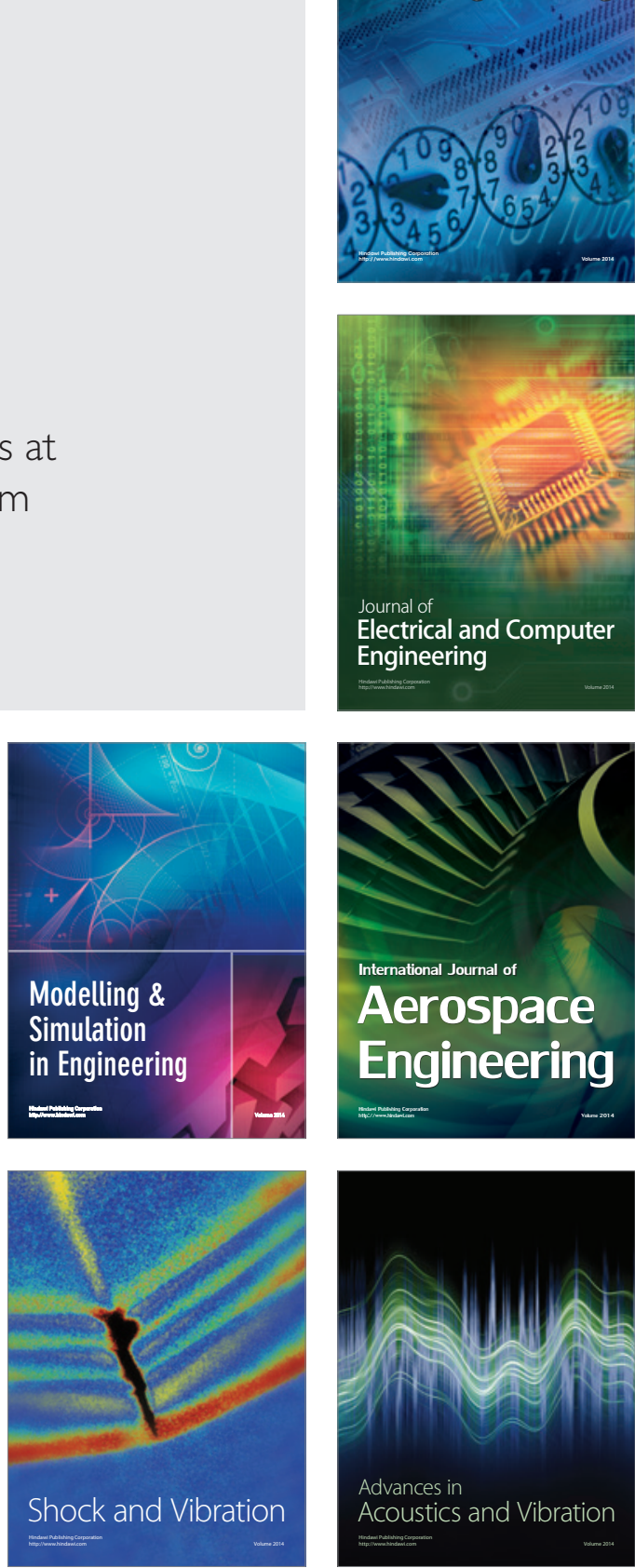